Cinémas

Revue d'études cinématographiques

Journal of Film Studies

\title{
Reading Positions, the Cow Bell Effect, and the Sounds of Silent Film
}

\section{Rick Altman}

Volume 2, numéro 2-3, printemps 1992

Cinéma et Réception

URI : https://id.erudit.org/iderudit/1001076ar

DOI : https://doi.org/10.7202/1001076ar

Aller au sommaire du numéro

Éditeur(s)

Cinémas

ISSN

1181-6945 (imprimé)

1705-6500 (numérique)

Découvrir la revue

Citer cet article

Altman, R. (1992). Reading Positions, the Cow Bell Effect, and the Sounds of Silent Film. Cinémas, 2(2-3), 19-31. https://doi.org/10.7202/1001076ar
Résumé de l'article

Cet article démontre les faiblesses de l'hypothèse historique de même que de l'hypothèse herméneutique dans l'approche des problèmes de réception. Étudiant les modalités relatives à certaines pratiques du film muet américain, l'auteur conclut qu'à la place de mettre l'accent sur les conditions culturelles des spectateurs comme élément fondamental dans les modifications de la réception, nous devrions nous pencher davantage sur la capacité des textes à contenir et contrôler leur propre réception. 


\title{
Reading Positions, the Cow Bell Effect, and the Sounds of Silent Film
}

\section{Rick Altman}

\begin{abstract}
RÉSUMÉ
Cet article démontre les faiblesses de l'hypothèse historique de même que de l'hypothèse herméneutique dans l'approche des problèmes de réception. Étudiant les modalités relatives à certaines pratiques du film muet américain, l'auteur conclut qu'à la place de mettre l'accent sur les conditions culturelles des spectateurs comme élément fondamental dans les modifications de la réception, nous devrions nous pencher davantage sur la capacité des textes à contenir et contrôler leur propre réception.
\end{abstract}

\begin{abstract}
This article demonstrates that both the historical hypothesis and the hermeneutic hypothesis are misleading in the approach regarding the problems of reception. Studying certain performance practices of American silent film, the author concludes that instead of positing cultural conditions for audiences as the basic catalyst for changes in reception, we need to pay greater attention to the capacity of texts to contain and control their own reception.
\end{abstract}


Over the last quarter-century we have witnessed a radical shift in the critical paradigms governing cinema studies. Increasingly, the notion of a standardized "spectator" has been replaced by a multiplicity of spectator groups interpreting films quite differently, each according to a different experience of the world and of texts. The monolithic state apparatus of an Althusser has thus given way to the reading formations of Tony Bennett, the archaeology of Michel Foucault, or the uncommon cultures of Jim Collins. At the same time, the subject of psychoanalysis has been broken down by gender, race, and class. The unitary genre-oriented approaches associated with structuralism, along with related text-based strategies, have now been supplanted by British Cultural Studies and other methods revealing increased sensitivity to specific audience segments and their experience.

Academic reception studies, we may note, developed in the wake of the communication industry's recognition of a change in television audiences. Commonly treated during the post war era as a single audience made up of generic viewers, television spectators have now for almost three decades been divided and sub-divided according to every possible characteristic. Dependent on demographic distinctions, targeted advertising is the order of the day, with programming decisions regularly based on increasingly detailed information about audience sub groups.

An important embodiment of postmodernism, this concordance between audience fragmentation and a shift in critical paradigm conceals two important flaws in the current understanding and practice of reception studies. In general, reception studies may be seen to rely on a pair of crucial assumptions. According to a fundamental historical hypothesis, the existence of more or less unified national communities assured broadly similar reception of texts until the postmodern fragmentation of the last quartercentury. This is why reception studies have concentrated on the reception of recent texts. According to an accompanying hermeneutic hypothesis, new reception situations can be interpreted only through new analytical techniques, such as those offered by recent critical methods sensitive to audience fragmentation.

Both of these assumptions deserve more careful scrutiny than 
I can provide in this article. In the space available here I can only explain why these two founding hypotheses are misleading, all the while sketching a more satisfactory approach to the problem of reception, based on certain performance practices of American silent film.

\section{The Historical Hypothesis}

The critics of the seventies and eighties rightly recognized that audiences and the entire reception process had changed since the fifties. They were wrong, however, to assume that audiences had always been as unitary as the unified postwar audience. On the contrary, the relative unity of audiences during the pre-1960s period represents not the continuation of centuries of unbroken uniformity of reception, but an exceptional situation engineered at the beginning of this century to maximize the budding mass communications market. The changes involved may best be understood by distinguishing three periods. I trust that readers will forgive the extreme simplification of this presentation, conducive as it is to clarity and fruitful debate.

\section{Audiences before 1900: fragmentation without communica- tion}

Before the automobile and the mass media, insufficient transportation and communication enforced a very real separation of groups and thus a multiplicity of possible audiences. At the same time, however, this very separation typically led most types of text to be reserved for a specific limited audience. Even though cultures were composed of differing groups, then, the reception of any particular text tended toward uniformity, given the artificial limitations placed on the size and variety of the audience.

In general, during this period separate audiences were allowed to evolve separately, with little effort to constitute a single overarching audience. Occasional exceptions were typically catalyzed by the necessities of military strength, national unity, religious coherence, or economic growth. Attempts at defining a national audience (i.e., market), for example, often derived from the preoccupations of a single class (e.g., the British bourgeoisie, the Dutch middle class, the Italian nobility), the taste of a single capital city (e.g., Paris), or needs associated with a particular 
educational level (e.g., the European book trade). It is important to note, however, that all of these attempts to constitute a single unified audience are partial and ideological. That is, they define a single market simply by denying the specific character of all non-conforming groups (the working class, provincials, the uneducated, etc.). Defining - indeed imposing — unity from above, these approaches regularly risk revolutionary reaction on the part of the excluded groups. ${ }^{1}$

\section{Unity as handmaiden of hegemony: mass-mediated audien- ces, 1915-1965}

The early years of this century were a time of radical variety in American audiences. Far from offering a unified population, large cities featured multiple communities of differing ethnic, religious, or national origins, self-consciously differentiated by ghettoized living arrangements, non-English-language newspapers, dietary particularities, characteristic festivals, and other constitutive traditions. In short, early American film audiences were anything but unified. On the contrary, they were symbolically diverse, overtly representing every possible national origin, ethnic background, religion, class, and race. How did such an extraordinary diversity become so quickly reduced to the unified audience that characterized American life until the sixties?

To an extent never experienced in the Old World, the American multiethnic Babel was a media-oriented world. Innovations like the telegraph, telephone, and cinema fostered contacts on a radically enlarged scale, resulting in an increasingly national public sphere. Coupled with intense and varied immigration, the rapid and untrammeled growth of American cities assured new types of interaction among groups. A thorough transformation of the social and economic structure, privileging effort and insight over birth and breeding, favored daily relations between individuals of differing backgrounds. For the first time, here was a truly diverse population nevertheless assembled into a single audience. Indeed, a new generation of media moguls had every incentive to combine diverse groups into a single larger, more lucrative audience. The profits from a German-language newspaper, a Yiddish play, or an Italian Opera could never match the income 
potential of a national English-language magazine or a program of silent films accompanied only by effects and music.

The first quarter of this century in the United States was thus a privileged arena for the creation of a single, integrated American audience. The major change involves not so much the disappearance of ethnic, national, and religious differences though there is a considerable leveling of audience differences during this period - but the "training" of diverse populations toward a common interpretation practice. The end result of this training is an audience made up of spectators who are different in fact (i.e., in language, customs, income, religion, needs, interests, etc.), but homogeneous in reception practices (i.e., in their method of understanding and employing texts).

How did this transformation come about? The details of the story cannot be recounted here. Suffice it to say that the post-Civil War period on the American stage had already laid the groundwork for this change, through the mixing of national and ethnic traditions in the typically American forms of minstrel show, burlesque, and vaudeville. Most important of all during cinema's formative period was the development of a type of melodrama involving identification with a culturally unspecific hero and heroine over against an exaggeratedly specific villain, with whom nobody identifies, not even those who share his nationality, religion, or physical traits. If this brand of melodrama became the very foundation of Hollywood classical narrative, it is because of its ability to satisfy the needs of diverse audiences indiscriminately. Partaking of this melodramatic tradition, audiences leave behind their own specificity, as they do with the songs of the June/moon tradition to which Hollywood owes the equally unspecific nature of its romantic plots. Sharable unspecifics - this is what it takes to turn diverse individuals into a single audience trained to read the same films in the same way.

The role of classical narrative conventions in this leveling of audience differences cannot be overestimated. Beyond the standardization involved in the broad dissemination of this style, the very construction of Hollywood films involves multiple methods of guiding spectators - independently of their real differences - toward shared interpretations. In a later section of 
this essay, I will explain some of the devices which make this homogeneity possible. As we shall see, twentieth-century modes of establishing unified audiences have little in common with previous methods of imposing unity. Whereas earlier approaches reflect the ideology of a specific ruling class (family, city, region, or religion), cinema's unifying strategies are fundamentally hegemonic in nature, dependent on the participants themselves to establish the reasoning and carry out the operations whereby a population of immigrants shed their differences in order to become a single audience.

\section{Fragmentation since the sixties: the making of the postmodern world}

It is a cliché of recent criticism that the reception situation has changed on a world-wide basis since the sixties. Not only have texts themselves taken on a characteristic post modern mix of styles, but audiences as well have become thoroughly fragmented. With few exceptions, there no longer exists a national audience, but instead an amalgam of special interest groups reacting diversely to every possible text. Despite a few overt attempts at assuring a truly national audience - for example, television, network news, all-day wartime special broadcasts, and the national journalistic strategies of USA Today - today's programming is dominated by demographic targeting and by clearly distinct reception groups.

Only rarely are American audiences conceived as American; instead they are yippie or yuppie; juvenile, thirtysomething, or golden age; NRA, PBS, or DAR; entry-level buyers, upscale, or top-of-the-line. The same text literally does not look the same to different spectators. Whereas some will recognize every car model, others will strain to pick up the dominant brand of designer jeans, while still others will notice every drop-out, jump cut, or mismatched edit. This tendency toward a flattened screen, where everything is equally open to spectator interest, is not entirely new, but as we shall see in the next section, the methods developed during cinema's formative years and exploited throughout Hollywood's classical period work directly against such flattening. 


\section{The Hermeneutic Hypothesis}

Reception-oriented criticism has depended heavily on the example apparently provided by the recent history of texts and audiences. Typically, critics recognize the social upheavals of the sixties, note the extent to which various affinity groups have since the sixties affirmed their separate existence (blacks, women, gays, and chicanos offering the clearest examples), and conclude that today's fragmented audiences are a result of fragmentation within the culture at large. The culture has been broken in pieces; piecemeal interpretation of texts must follow.

In short, the guiding hermeneutic hypothesis of reception criticism includes the notion that spectators develop their reading formations through their contact with the world at large, then bring that reading formation to specific texts; reception studies must deal directly with cultural concerns because it is within the culture that we can find the key to understanding the diverse interpretations associated with various reading formations. Strangely, this approach assumes a fundamental separation between texts and culture, thus begging the question of the role of texts within culture. For reading formations cannot possibly simply be formed in the world and then brought to texts, because texts are a fundamental part of that world; reading formations are heavily influenced and in some cases even wholly formed by texts. In reacting against generations of text-based criticism, proponents of reception studies have often gone too far, denying to texts their potentially active role in the processes of culture.

This is especially true in cases where critical activity is already inscribed within the text (i.e., where the text offers a model for its own reading). Starting over a decade ago, Jane Feuer and I showed that certain stylistic features usually taken as the radical tools of modernism - like self-consciousness and reflexivity serve within the Hollywood tradition (notably in the musical genre) a totally different function. ${ }^{2}$ In a similar manner, it is now time to recognize that overt awareness of the reader's activity, long alleged as an especially innovative and liberating aspect of modernism, often takes on an altogether different function in the cinema. While the mise-en-abîme resulting from imbedding the reader's position within the text itself can radically complicate a 
text, increasing its ambiguity and thus fragmenting its reception (as in the case of Joyce, Gide, Woolf, and other modernist novelists), a more conservative use of the same technique permits "silent" films to reduce ambiguity, thereby assuring uniformity of reception. This process is primarily carried out by what we might call the silent film's "sound track" (music and sound effects). It involves a) reduction of the text's potential heterogeneity, which is effected by b) giving narrative relief to the flat photographic screen, thus producing $\mathrm{c}$ ) a reading position within the text which spectators (who are also auditors) are hard put not to share.

These claims will be much clearer in the light of a few examples from the early history of American cinema. From 1909 to the early teens, critics waged an extended debate on the role that sound effects should have in the cinema. Attacking the overtly discursive vaudeville practice of using sound effects primarily for comic effect, these critics were instrumental in developing, by the mid-teens, the preference for discreet narrative effects that would characterize a half-century of Hollywood cinema. Around 1910, the trade papers abound in disapproving descriptions of effects specialists (typically drummers working a series of "traps") who labor mightily to reproduce every possible sound suggested by the image. Like many others, H. F. Hoffman insists that it is important not to "detract from the acting by jangling a cow bell when it has no bearing on the picture" (185). This formulation is in every way striking. If the drummer has chosen to play a cow bell at a particular point, it is surely because he has seen a cow in the picture. How then can it reasonably be said that the cow bell "has no bearing on the picture"? Obviously, the term "picture" has here - and throughout the formative period in question - taken on a new meaning. A picture is no longer a photograph, flat and neutral, with all parts constantly available to the spectator's gaze. Instead, the surface of the photograph has been diversely charged by cinema's narrative power source. ${ }^{3}$ Whereas some parts of the image are abandoned by the narrative (the cow), others take on a powerful role in the image's new hierarchy (the actors). "Do not pay so much attention to trivial things just because they happen to be in the picture," says Hoffman. "Get in with the sound that ought to be there..." (185). Terms like "trivial," "happen," and "ought" 
tell us a great deal about this new definition of the cinema.

Having spent the years immediately prior to 1910 developing a panoply of new "instruments" facilitating the production of every possible sound suggested by the film image, effects specialists now found themselves faced with a new problem: how to decide which effects to play, and when to remain silent. Drummers had to learn how to avoid what we might call the cowbell effect. Instead of indiscriminately reproducing all the sounds implied by a neutral image, they had to make rapid and informed decisions about which sounds might make the most appropriate contribution to the film's overall design. "Each picture," says Stephen Bush, "must be studied by itself and only such effects introduced as have a psychological bearing on the situation as depicted on the screen" (690). According to Bush, this lesson is a thing of the past for the vast majority of effects specialists. Writing in 1911, he affirms that "the imitation of common and obvious sounds has long ago been abandoned by nine out of every ten exhibitors, who, quite wisely will rather dispense with effects altogether than risk monotonous or misplaced or ill-judged effects" (690).

The secret of this progress, according to Bush and others, lies in the growing ability of effects specialists and musicians alike to interpret the relative value of the various aspects of the image. Everywhere exhorted to preview the film, drummers and musicians take on a special role in the reception process. On the one hand, they are part of the production team, the final contributors to a finished film product. On the other hand, they are each film's first spectators. Like contemporary film critics, the producers of music and effects were typically the only ones to view a truly silent film. As we have seen, however, their role changes rapidly from observer to interpreter. According to Clarence E. Sinn, "Cue Music Man" for the Moving Picture World, "One must fix on the predominant theme of a picture and work to that. This theme always centers in the principal characters of the play" (December 10, 1910: 1345). More specifically, says Sinn, "I have noticed a tendency among some pianists to play to the details of a picture rather than to the story itself." Instead, he counsels, "don't pay too much attention to the little details and the accessories of a picture unless they have an important bearing on the scene or the story" 
(december 31, 1910: 1531). On the very same day, Clyde Martin, film music columnist for the Film Index, explains how he exploits his understanding of the film's devices. "I make it a point," he says, "to "work up" the entrance of the popular stars and it never fails that the audience gives them a round of applause" (12). Quite clearly, Martin has not only studied each particular film, but he has learned a great deal about the role of stars in the narrative economy of early cinema.

Writing a decade later, Edith Lang and George West offer a still more pithy lesson for pianists. "The player should, above all," they affirm, "learn to read facial expressions" (5). ${ }^{4}$ Note how this leitmotif returns incessantly: preview, study, read. Again and again, contemporary writers stress the musician's role (along with that of the effects specialist) as critic, as interpreter, in short as reader of the film. The silent film sound track thus offers a reading position that serves as a basic model for all subsequent viewers. Built into the film, this reading position guarantees a certain homogeneity of reception on the part of the most heterogeneous audiences.

Curiously, contemporary musicians appear somewhat troubled by their role as "master reader." Starting in the teens, in order to conceal the fact that film music is conceived not as part of the original film but as a post hoc reaction to the film, music critics regularly stress the importance of making each musical theme anticipate the filmic events to which it is related. ${ }^{5}$ By displacing their reactive music, musicians thus hide their role as spectators. Through careful synchronization, effects appear to arise from the image, with which they therefore seem coeval; in the same way, the musical practice of anticipating image events bonds the sound to the image, disguising its status as a critical act born out of a prior experience of spectatorship. Effects and music alike thus serve a fundamental function of what we might term "imbedded reception," the inclusion of the reception process as part of the elaboration of the text itself.

In passing, I note that musicians and effects specialists a like must have possessed an extraordinarily high level of understanding of the incipient classical narrative system. In seeking the sources of Hollywood's classical system, scholars have paid careful attention to the innovations of directors like Griffith and Ince, but 
they have shown too little understanding of the tacit knowledge demonstrated by sound artists. Too often, the history of cinema has concentrated on the top-level decision makers, remaining unfortunately oblivious to the internalized understanding of technicians. When these technicians happen to be the readers who provide the model reading positions for a generation of film viewers, then it is time for the importance of their role to be more openly acknowledged.

Much more deserves to be said about the role of music in homogenizing the American audience from the teens on. In particular, the constant use of regional American songs during the teens offers an especially unexpected common ground for spectators of extremely diverse backgrounds. Cinema organists must know by heart the tunes of Stephen Foster, says Montiville Morris Hansford, the Daily Mirror's film music columnist. "They will be found pleasing to the audience, because nearly everyone knows them and they bring up old memories" (12). It is hard to imagine what memories "My Old Kentucky Home" could evoke in an Irish, Czech, or Italian immigrant, not to mention a Black or Native American. Exploiting common ground where they found it, creating commonality where they found none already existing, early film musicians played a major role in initiating a halfcentury of audience unity.

After World War I, the ethnic press slowly disappeared in the United States, along with ethnic theater and other ethnic events. It has regularly been assumed that this process is a natural effect of lost interest in ethnic concerns, understandable in the American melting-pot. Acknowledging that reception depends on more than cultural upheaval, that it can be engineered for purposes of an economic or ideological order, we easily recognize that the decline of ethnicity is in large part the direct result of massmediated substitution of "American" interests and narrative investments for ethnic news and traditions.

Instead of positing cultural conditions for audiences as the basic catalyst for changes in reception, we need to pay greater attention to the capacity of texts to contain and control their own reception. Through the deployment, in particular, of an inscribed reading position - often dependent on a second medium such as 
sound or the printed word - texts can be engineered to homogenize their audiences. Just as the texts of post-modernism have perfected a panoply of indeterminacy effects, designed to assure ambiguity and heterogeneous reception, Hollywood classical narrative proved capable, from its very infancy, of dissolving multiple reading formations into a single reading position.

\section{University of Iowa}

\section{NOTES}

1 A more thorough treatment of this topic would foreground the importance of the development of national languages as a fundamentally hegemonic method of reducing the interpretive effect of differing audience reading formations.

2 See especially Feuer's essay in Genre: The Musical, ed. Rick Altman(London \& Boston: Routledge and Kegan Paul, 1981), as well as her The Hollywood Musical (Bloomington: Indiana University Press, 1982) and my own The American Film Musical (Bloomington: Indiana University Press, 1987).

3 One of the ultimate effects of this new hierarchization of the image is to create a basic but little recognized aspect of Hollywood classical narrative that I have called the "foreground/background system." Heavily influenced by the biplanar photographic practices of song-slide manufacturers (backgrounds are sought out or created by one team, while another conceives the foreground narrative representing the words of the song), the foreground/background system culminates in the background projection techniques that characterize the production of Hollywood sound films. Whatever the process used, the effect is always the same: to channel viewer interest toward certain parts of the image, while leaving other parts in the background. For more on the foreground/ background system see Rick Altman, (ed.), Sound Theory/Sound Practice (New York: Routledge, 1992).

4 Italics in original.

5 For example, in Lang and West, op. cit., p. 3.

WORKS CITED

Bush, Stephen W. "When "Effects" Are Unnecessary Noises." Moving Picture World (September 9, 1911). 
Hansford, M. M. "Preparing Programs for Photoplay Accompaniments." Daily Mirror (September 1, 1917).

Hoffman, H. F. "Drums and Traps." Moving Picture World (June 23, 1910).

Lang, Edith and West, George. Musical Accompaniment of Moving Pictures: A Practical Manual for Pianists and Organists and an Exposition of the Principles Underlying the Musical Interpretation of Moving Pictures. Boston: Boston Music Co., 1920.

Martin, Clyde. "Playing the Pictures." Film Index (December 10, 1910).

Sinn, Clarence E. "Music for the Pictures." Moving Picture World (December 10, 1910).

Sinn, Clarence E. "Music for the Pictures." Moving Picture World (December 31, 1910). 